\title{
Ceramic nanoparticles and carbon nanotubes reinforced thermoplastic materials for piezocapacitive sensing applications
}

\author{
T. Marinho ${ }^{1}$, P. Costa ${ }^{1,2}$, E. Lizundia ${ }^{3,4}$ C.M. Costa ${ }^{1,5^{*}}$, S. Corona-Galván ${ }^{6}$, S. Lanceros- \\ Méndez ${ }^{4,7}$
}

${ }^{1}$ Center of Physics, University of Minho, Campus de Gualtar, 4710-057 Braga, Portugal ${ }^{2}$ Institute for Polymers and Composites IPC/i3N, University of Minho, 4800-058 Guimarães, Portugal

${ }^{3}$ Department of Graphic Design and Engineering Projects, Bilbao Faculty of Engineering, University of the Basque Country (UPV/EHU), Bilbao 48013, Spain

${ }^{4}$ BCMaterials, Basque Center Centre for Materials, Applications and Nanostructures, UPV/EHU Science Park, 48940 Leioa, Spain

${ }^{5}$ Center of Chemistry, University of Minho, Campus de Gualtar, 4710-057 Braga, Portugal

${ }^{6}$ Dynasol Elastómeros, Titán, 15, $9^{\text {th }}$ Floor, 28045 Madrid, España

${ }^{7}$ IKERBASQUE, Basque Foundation for Science, 48013 Bilbao, Spain

\begin{abstract}
This work reports on the development of polymer composites for load sensing applications. Three thermoplastic polymers, one with elastomeric behaviour, namely poly(styrene-butadiene-styrene) and poly(styrene-ethylene/butylene-styrene), and a semi-crystalline fluorinated polymer, poly(vinylidene fluoride), were selected as hosting matrices. In order to improve the sensing capacity, both ceramic nanoparticles (barium titanate, BT) and carbon nanotubes (CNTs) have been incorporated through solvent mixing followed by spreading the solution onto a glass substrate and subsequent solvent evaporation. Scanning electron microscopy results show that nanoparticles remain uniformly distributed through the nanocomposite at concentrations as high as $50 \%$ by weight. Polymer-filler interactions and thermal stability of the nanocomposites were assessed by Fourier transform infrared spectroscopy and thermogravimetric analysis,
\end{abstract}


respectively, in which these nanocomposites present physical interaction between constituents rather than chemical interaction and thermal stability increases slightly for larger filler contents. The mechanical properties are dependent on the matrix, filler type and amount in which the incorporation of both fillers in the elastomeric matrices increases the initial modulus of the nanocomposites up to 3-times. Electrically insulating BT increases dielectric properties and electrically conducting CNTs increase the dc conductivity of nanocomposites, respectively, and the combination of both fillers results in a synergetic effect. Finally, the changes induced by applied static loads on the capacitance variation $(\Delta C)$ of the nanocomposites were evaluated, showing a marked enhancement on the $\Delta C$ upon the incorporation of both fillers due to the synergetic effect provided by electrically insulating BT together with electrically conducting CNTs.

Keywords: A. carbon nanotubes; A. Nano particles ; A. Nano composites; A. Polymermatrix composites (PMCs); A. Smart materials

\section{Introduction}

During the last decades, high dielectric polymeric materials have been increasingly investigated due to both scientific and technological interest as they combine tuneable dielectric properties together with a proper mechanical flexibility [1-3]. Such composite materials show a plethora of opportunities to be implemented in devices such as electronics [1], electromagnetic interference shielding [4], sensors and actuators [5].

Polymeric matrices such as thermoplastic elastomers (TPEs) are characterized by large deformations to rupture (up to 1000\%), making them interesting candidates for the development of large deformation and rapid elastic recovery stimuli-responsive materials [6] [7]. Among TPEs, poly(styrene-b-butadiene-b-styrene) (SBS) and related polymers have shown large potential to develop strain and force sensors for small and large 
deformation applications [8]. Moreover, the SBS family of polymers are thermally stable, show simple processing and their production cost is relatively low.

Although with excellent processability and mechanical properties, the low dielectric constant of SBS family of polymers limits their applicability in areas such as energy storage [9], electromechanical transducers [10], or capacitive sensing [11]. Conversely, ferroelectric polymers such as poly (vinylidene fluoride) (PVDF) show a larger permittivity from 6 to 12, depending on the polymer phase [12], which is one of the largest obtained among polymers, but still low in comparison with many inorganic dielectrics [13]. Further, this family of polymer, when crystallizing in specific phases also show piezoelectric response [14], highly used for sensor and actuator applications.

In this context, a suitable strategy to increase the dielectric constant and functional performance of polymer materials would be the incorporation of high permittivity nanofillers to obtain a hybrid material with large dielectric constant $\left(\varepsilon^{\prime}\right)$, and then uniformly disperse a conducting third phase to further enhance their dielectric properties [15]. Due to synergetic effects among fillers, the presence of such secondary nanoparticles may endow composites with tailored electrical performance without harming mechanical or thermal properties. Further, together with increased dielectric response, reinforced polymers with appropriated conductivity also can show suitable piezoresistive response [16].

In this framework, ceramic materials such as barium titanate (BT) display high dielectric constant, making them suitable candidates for the development of polymer composites with enhanced dielectric response [17, 18]. Moreover, conducting nanofillers such as graphene or carbon nanotubes (CNTs) can be introduced into polymeric hosts to tune and improve the electrical [19], thermal [20] and mechanical properties [21]. In particular, comparing with other carbonaceous fillers, the long aspect ratio and low cost 
of CNTs make them excellent reinforcing fillers to develop piezoresistive composites with low percolation threshold, i.e., they are able to form a conductive network which provides electrically conducting properties to the whole composite [16]. With respect to two composite systems, it has been shown the suitability of secondary fillers such as clays in percolative composites [22]. Considering that each filler has different properties, recently, composites with two different fillers have been intensively studied for PVDF [23]. The combination of these fillers is varied may be two insulating $\left(\mathrm{BaTiO}_{3}\right.$ and $\mathrm{Al}_{2} \mathrm{O}_{3}$ nanoparticles)[24], an insulator and conductive $\left(\mathrm{BaTiO}_{3}\right.$ and reduced graphene oxide) [25], other magnetic and conductive $\left(\mathrm{Fe}_{3} \mathrm{O}_{4} / \mathrm{MWNT}\right)$ [26], etc. For the SBS and SEBS elastomer matrix, tri-composites are still poorly exploited.

In this work we report on the fabrication of polymer composites for pressure and deformation sensing applications based on two polymer matrices family and two different fillers (electrically insulating $\mathrm{BaTiO}_{3}, \mathrm{BT}$ and electrically conducting CNTs) with different fillers amount.

Two polymer matrices have been selected, the SBS and SEBS elastomers and the thermoplastic PVDF. The synergetic effects of CNTs and BT introduction within the polymers on the thermal, mechanical, electrical and sensing performance were explored.

The piezocapacitance of these nanocomposites has been evaluated for a wide range of potential applications including pressure and deformation sensing, among others. 


\section{Materials and methods}

\subsection{Materials}

The used thermoplastic elastomers (TPE) were styrene-butadiene-styrene (SBS) with reference 718 , showing radial structure and 75/25 butylene/styrene ratio and styreneethylene/butylene-styrene (SEBS) with reference 108C and 85/15 ethylenebutylene/styrene ratio. Both SBS and SEBS were supplied by Dynasol Elactomers, S.A (Spain). Commercial Solef 1015 poly(vinylidene fluoride) (PVDF) with a $M_{w}=300.000$ $\mathrm{g} \cdot \mathrm{mol}^{-1}$ was supplied by Solvay, Inc. (Belgium). Multi-walled carbon nanotubes (CNTs) with a purity of $90 \%$, outer mean diameter of $9.5 \mathrm{~nm}$ and length of $1.5 \mu \mathrm{m}$ were supplied by Nanocyl (reference NC7000). Barium titanate (BT) nanoparticles with an average size of $500 \mathrm{~nm}$ were obtained from Nanoamor (USA). Cyclopentyl methyl ether (CPME) was used as a solvent to process both SBS and SEBS and was supplied by Carlo Erla ( $\rho: 0.86$ g. $\mathrm{cm}^{-3}$ at $20^{\circ} \mathrm{C}$; boiling point: $106^{\circ} \mathrm{C}$ ). For dissolving PVDF, N,N-dimethylformamide (DMF, 99.5\%), from Merck, was used.

\subsection{Composite preparation}

PVDF, SBS and SEBS composites were prepared using similar processing conditions (Table 1), with a solvent/polymer ratio of $80 / 20 \mathrm{vol} / \mathrm{vol}$ for all composites. For the processing of PVDF, DMF was used as a solvent, while both SEBS and SBS were dissolved in CPME. The effect of ceramic particles into PVDF matrix was demonstrated in $[27,28]$, the dielectric constant increasing with increasing filler content. Typically, the $50 \mathrm{wt} . \%$ of ceramic fillers is the maximum of filler for obtaining films with suitable mechanical properties [29] while maximizing the dielectric response of the composite [30]. Neat PVDF and composites having 0.15, 0.25 and 4 wt.\% CNTs and 50 wt.\% BT were fabricated. 
Firstly, the respective amount of DMF and nanofillers were placed in a beaker during $3 \mathrm{~h}$ in ultrasonic bath at $25-35^{\circ} \mathrm{C}$ for homogeneously dispersion of the nanoparticles. The effect of the CNT amount on SBS and SEBS composites was observed in $[6,16]$ where the polymer matrix affects the electric properties and the percolation threshold is above of 0.5 wt. $\%$ of CNT for all matrices.

SBS and SEBS composites were produced using the same first step processing, but the solvent used was CPME. The SEBS composites were fabricated using 0.5 wt.\% CNTs and 50 wt.\% BT. Additionally, a tri-composite based in SEBS with 0.5 wt.\% CNTs and 50 wt.\% BT was obtained, allowing to evaluate the synergetic effect of having both dielectric and conductive filler. To compare the effect of the polymer matrix an SBS composite with $50 \mathrm{wt} . \%$ BT was also obtained. The resulting mixture was magnetically stirred for $3 \mathrm{~h}$ at $30^{\circ} \mathrm{C}$.

Mechanically flexible composite thin films with thickness between 20 and $100 \mu \mathrm{m}$ were obtained by spreading the solution on a clean glass substrate followed by solvent evaporation at different temperatures: SEBS and SBS-based composites were dried at 30 ${ }^{\circ} \mathrm{C}$ for $12 \mathrm{~h}$, while PVDF composites were dried at $210{ }^{\circ} \mathrm{C}$ for 15 min (melting and recrystallization procedure $[12,14])$.

Table 1. Pristine polymers and corresponding composites produced in this work and the nomenclature for the different materials.

\begin{tabular}{|c|c|c|c|}
\hline Samples & PVDF & SEBS & SBS \\
\hline $\begin{array}{c}\text { Solvent/polymer } \\
\text { ratio (vol/vol) }\end{array}$ & DMF/PVDF(80/20) & CPME/SEBS (80/20) & CPME/SBS (80/20) \\
\hline & $0.15 \mathrm{CNT} / \mathrm{PVDF}$ & & \\
& $(0.15 \mathrm{wt} . \% \mathrm{CNT})$ & & \\
& $0.25 \mathrm{CNT} / \mathrm{PVDF}$ & $0.5 \mathrm{CNT} / \mathrm{SEBS}$ & \\
Nomenclature & $(0.25 \mathrm{wt} . \% \mathrm{CNT})$ & $(0.5 \mathrm{wt} . \% \mathrm{CNT})$ & \\
and & $4 \mathrm{CNT} / \mathrm{PVDF}$ & & \\
filler contents & $(4 \mathrm{wt} \% \mathrm{CNT})$ & & $50 \mathrm{BT} / \mathrm{SBS}$ \\
& $50 \mathrm{BT} / \mathrm{PVDF}$ & $50 \mathrm{BT} / \mathrm{SEBS}$ & $(50 \mathrm{wt} . \% \mathrm{BT})$ \\
\hline
\end{tabular}




\begin{tabular}{|l|c|c|l|}
\hline & & $0.5 \mathrm{CNT} / 50 \mathrm{BT} / \mathrm{SEBS}$ & \\
& $(0.5 \mathrm{wt} \%$ CNT;50wt $\% \mathrm{BT})$ & \\
\hline
\end{tabular}

\subsection{Sample characterization}

The dispersion of the CNT and BT nanoparticles within the polymeric matrix was evaluated by surface scanning electron microscopy (SEM). Before analysis, samples were coated with a thin gold layer $(\approx 10 \mathrm{~nm})$ using sputter coating (Polaron SC502).

Infrared spectra in attenuated total reflectance mode (ATR) were recorded with a Jasco FT/IR-4100 apparatus. 64 scans were obtained in the range $600-4000 \mathrm{~cm}^{-1}$ with a resolution of $4 \mathrm{~cm}^{-1}$.

The thermal stability of the samples was studied with a Q500-TA instruments set-up under nitrogen atmosphere with a constant flow rate of $40 \mathrm{~mL} / \mathrm{min}$. Ceramic crucibles with capacity of $60 \mu \mathrm{L}$ were used as sample holders and the composites were analysed in the temperature range from 40 to $700{ }^{\circ} \mathrm{C}$ with a heating rate of $20^{\circ} \mathrm{C} / \mathrm{min}$.

Mechanical measurements were performed using a Shimadzu model AG-IS machine with a load cell of $500 \mathrm{~N}$ using rectangular samples $\left(15 \times 20 \mathrm{~mm}^{2}\right.$; thickness between 20 $100 \mu \mathrm{m})$. Tensile strain testing at room temperature was performed at a speed of 5 $\mathrm{mm} / \mathrm{min}$. The initial modulus was measured up to $10 \%$ in SBS, SEBS and corresponding composites, and up to $1 \%$ for PVDF and composites. The compression mode tests were performed under the same conditions at forces up to $400 \mathrm{~N}$.

The room temperature volume electrical resistance of the samples was calculated from the slope of I-V curves measured in a Keithley 6487 picometer/voltage source. The samples were previously coated with $5 \mathrm{~mm}$ diameter gold electrodes (Polaron SC502) to ensure a good electric contact in both sides. The applied voltage was between -10 to +10 $\mathrm{V}$ and the corresponding current was measured. Measurements were obtained at three 
different positions of the samples. Then, the electrical conductivity $(\sigma)$ was calculated considered the geometrical factors of samples. Dielectric measurements were performed using a Quadtech 4000 by recording the capacity and the tan $\delta$ in the frequencies from $200 \mathrm{~Hz}$ to $1 \mathrm{MHz}$ at room temperature. The real and imaginary parts of the permittivity were obtained taking into account the parallel plate condenser geometry and the geometrical characteristics of the samples

The piezocapacitance of the composites was measured using the universal testing equipment Shimadzu with load cell of 500 N simultaneously with Quadtech 4000 equipment, to evaluate the performance of the composites under compression, up to 400 N. The dielectric behaviour of different polymers and corresponding composites was measured without applied force and at force values of 50, 100, 200 and $400 \mathrm{~N}$. 


\section{Results and discussion}

\subsection{Morphological analysis}

The overall macroscopic properties of nanocomposites strongly depend on the nanoparticle dispersion within the polymeric matrix [21] and, therefore, the morphology of the prepared materials has been firstly evaluated by SEM. Accordingly, Figure 1 shows representative SEM micrographs of the top surface of the prepared composite samples. The rest of the samples show similar features to the ones explained in the following. No CNTs aggregates can be noticed in Figure 1a as CNTs are observed as a small bright and well-dispersed on the surface of the SEBS matrix. This behaviour is similar for the remaining CNTs composites. The much larger size and amount of BT particles make them easier to spot when comparing with CNTs. As depicted in Figure 1b for 50BT/SEBS composites, although some well-dispersed particles can be observed, incorporated BT mainly aggregates in clusters with a size of few microns. In any case, taking into account that the mass loading of BT is $50 \mathrm{wt} \%$, it can be stated that a rather homogeneous dispersion has been obtained.
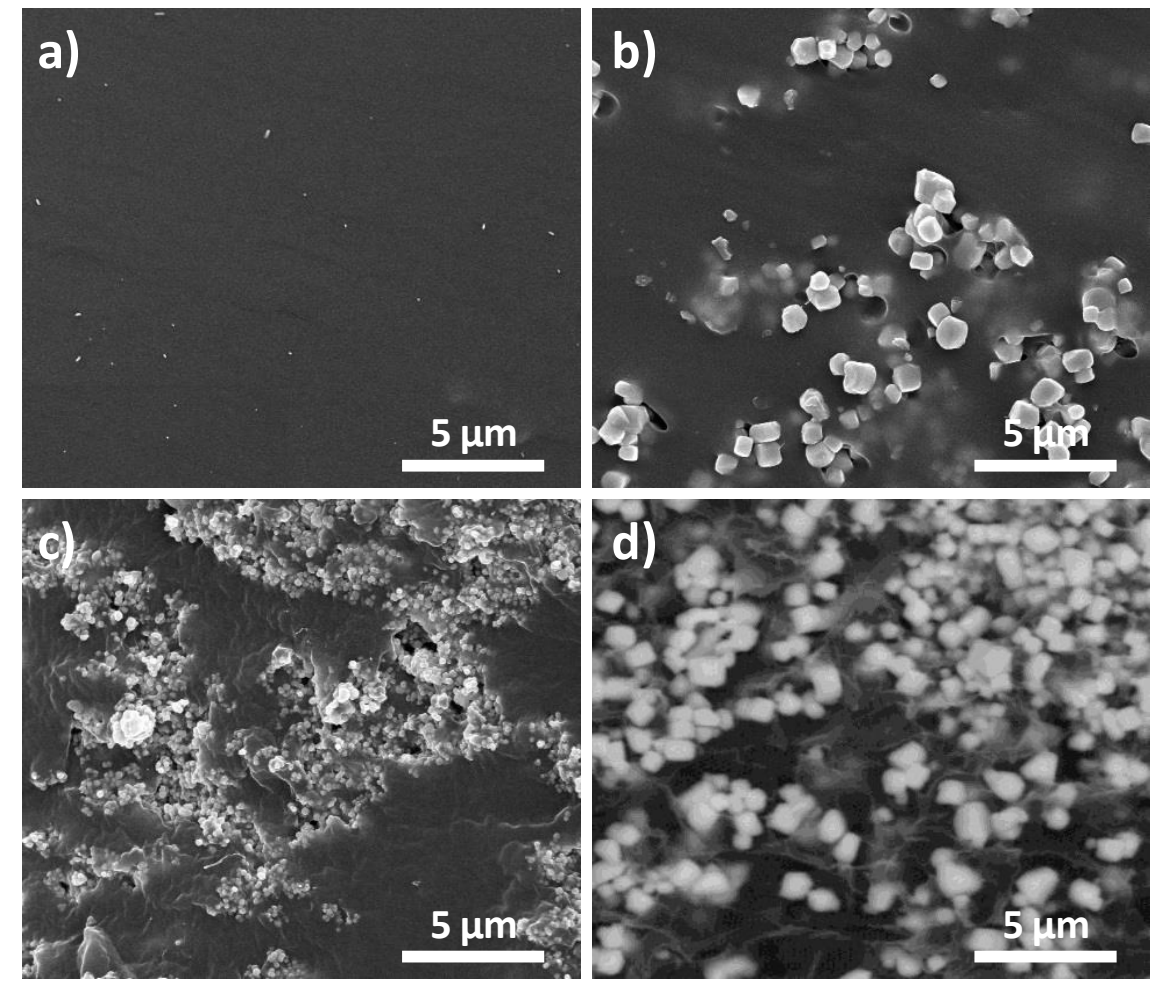
Figure 1 - SEM micrographs of the top surface of: a) 0.5CNT/SEBS; b) 50BT/SEBS; c) 0.5CNT/50BT/SEBS and d) 50BT/PVDF.

Although when comparing with 50BT/SEBS, 0.5CNT/50BT/SEBS tri-composite in Figure 1c shows larger agglomerates, it is observed that most of the regions are reinforced by nanoparticles. Finally, according to Figure 1d, the dispersion of BT within PVDF is comparable to that obtained for SEBS. For SBS matrix, it is observed the same behaviour to SEBS matrix. Interestingly, the degree of dispersion here achieved is similar to that previously obtained for BT/CNT/PVDF hybrid nanocomposites fabricated by a miscibleimmiscible coagulation method followed by hot pressing [15]. It can be concluded that BT remains uniformly distributed through the nanocomposite even though its concentration is as high as $50 \%$, by weight. The good dispersion is slightly affected by the presence of a small amount of CNTs to yield nanocomposites with agglomerated regions. Overall, the solvent based fabrication procedure here reported results an efficient and simple method to obtain well-dispersed highly filled nanocomposites, which is a typical challenge towards the development of materials with significantly enhanced electric and dielectric properties with other processing methods, such as hot pressing [31] or extrusion [32].

\subsection{FTIR results}

Fourier transform infrared spectroscopy (FTIR) has been performed to detect possible interactions between the reinforcing phase and the polymeric matrix as well as structural modifications in the polymer phase. Figure 2a) shows the FTIR spectra for the nanocomposites based on SEBS and SBS. As shown in Figure 2a), both neat SEBS and SBS present a very similar spectrum, with characteristic styrene and butadiene absorption bands. Both SBS and SEBS present several absorption peaks in the $3000-2800 \mathrm{~cm}^{-1}$ region associated with the $\mathrm{C}-\mathrm{H}$ aliphatic groups [33], together with sharp peaks located 
at 1493 and $1454 \mathrm{~cm}^{-1}$ arising from the aromatic $\mathrm{C}=\mathrm{C}$ stretching of styrene [34]. The peak at $699 \mathrm{~cm}^{-1}$ results from the ring out-of-plane deformation vibrations of the phenyl group [35]. The chain-structure differences between both SBS and SEBS are observed as a new peak at $966 \mathrm{~cm}^{-1}$ due to the trans-vinyl group of SBS (which is absent in the SEBS) and the $1373 \mathrm{~cm}^{-1}$ peak which is solely observed for SEBS and arises from the aliphatic C-H bending [36]. For SEBS-based composites, CNT addition does not affect the absorption bands of the SEBS polymer.

For both SBS and SEBS-based composites, BT addition results in a baseline deviation for wavelengths below $\approx 720 \mathrm{~cm}^{-1}$ due to the strong absorption centred at $540 \mathrm{~cm}^{-1}$ as a result of the Ti-O octahedron vibration [37]. Interestingly, it is observed that no new characteristic absorption bands for tri-composite appear with the incorporation of CNTs or BT, independently of the filler concentration. Moreover, the characteristics bands of SBS and SEBS do not shift, indicating that the prepared composites present a physical interaction between constituents rather than chemical interaction $[38,39]$.
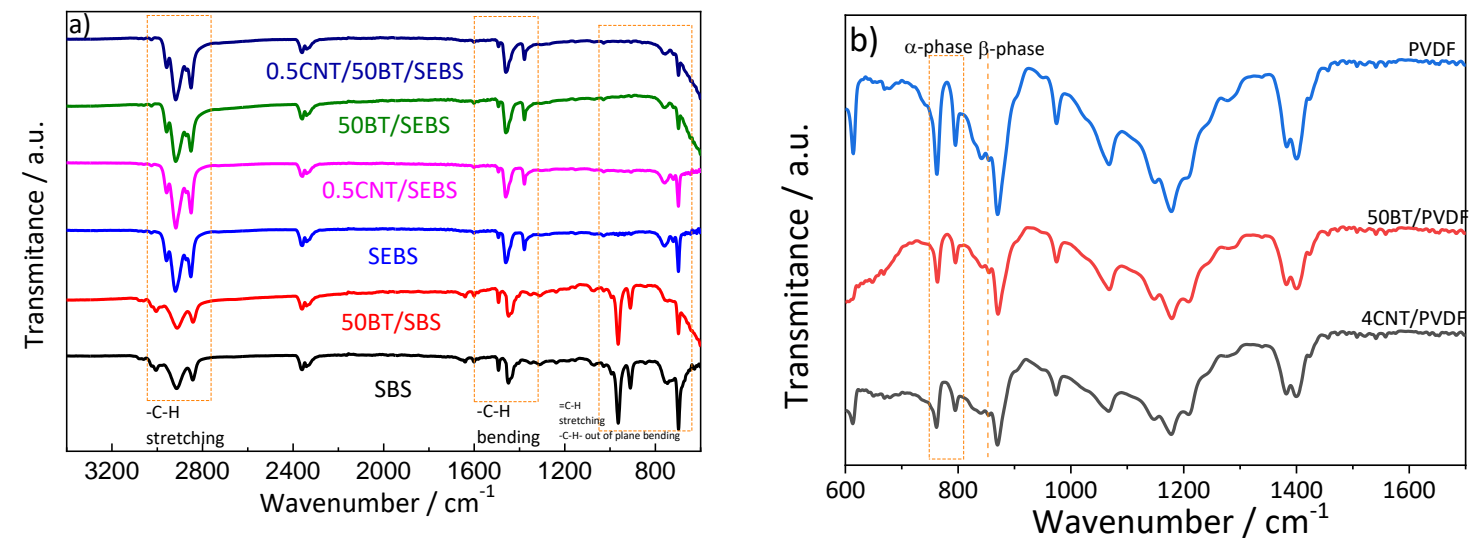

Figure 2 - FTIR spectra of the prepared composites based on a) SBS and SEBS elastomers matrices and b) thermoplastic PVDF.

Figure $2 b$ ) shows the FTIR spectra of the composites produced with PVDF polymer matrix. It is observed that PVDF phase is the $\alpha$-phase (peaks at $766 \mathrm{~cm}^{-1}$ and $795 \mathrm{~cm}^{-1}$ 
[12] and this behaviour is similar for neat PVDF and their respective composites. The inclusion of BT and CNTs does not produce any shift in the PVDF characteristics peaks, and no additional peaks appear in the spectra, either.

\subsection{Thermal stability}

The influence of CNTs and BT on the thermal stability of SBS, SEBS and PVDF matrices has been analysed by thermogravimetric analysis (TGA). Figure 3 shows the thermogravimetric (a) curves and weight loss (b) rates of neat SBS, SEBS and PVDF as well their nanocomposites, while the corresponding characteristic thermodegradation temperatures are summarized in Table 2 . The weight loss at a temperature of $300{ }^{\circ} \mathrm{C}$ is below $1 \%$ for all the compositions, indicating a good thermal stability and complete elimination of the residual solvent upon drying.
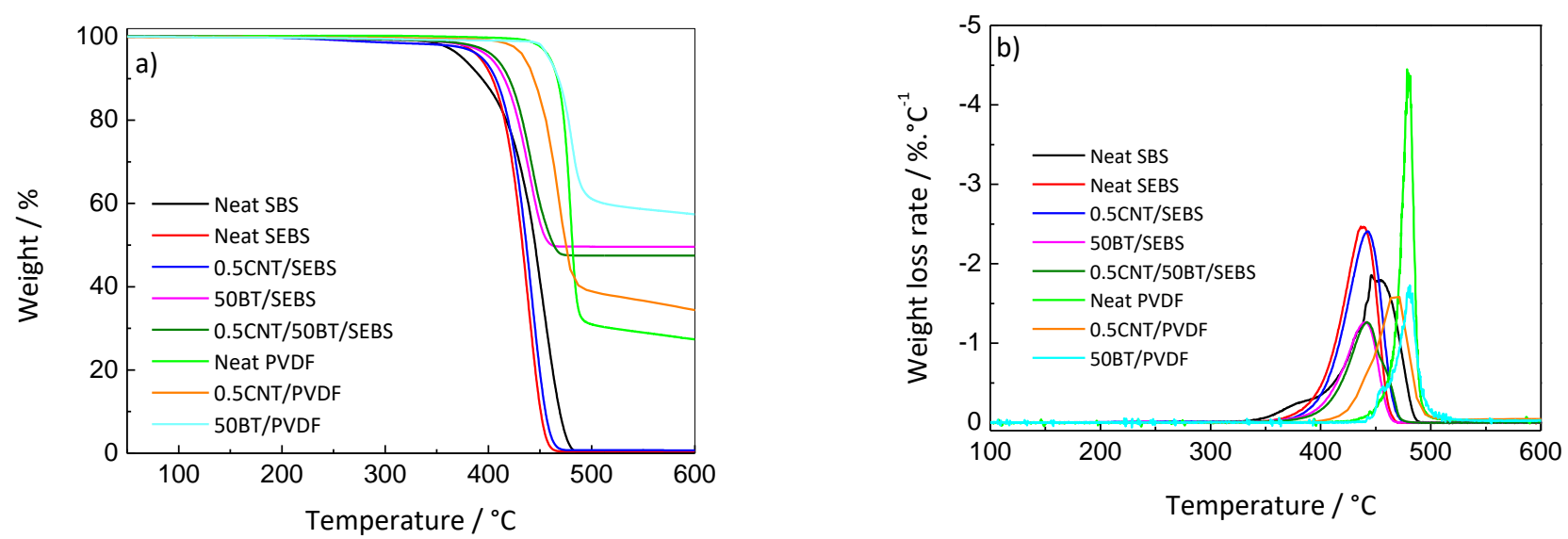

Figure 3 - (a) Thermogravimetric curves and (b) and weight lost rates of neat SBS, neat SEBS, neat PVDF and their nanocomposites obtained at a heating rate of $20{ }^{\circ} \mathrm{C} \cdot \mathrm{min}^{-1}$ under $\mathrm{N}_{2}$ atmosphere.

The degradation of neat SBS and SEBS takes place in a single step, beginning at 374 and $391{ }^{\circ} \mathrm{C}$ respectively (as determined by the first $5 \mathrm{wt} . \%$ weight loss, $T_{5} \%$ ) and reaching its maximum weight loss rate $\left(T_{p}\right)$ at 453 and $439^{\circ} \mathrm{C}$ respectively. In relation to the PVDF 
polymer, it is observed that all PVDF composites are stable at $400{ }^{\circ} \mathrm{C}$ and show two degradation steps characteristics of the PVDF polymer. The degradation step between $420^{\circ} \mathrm{C}$ and $500{ }^{\circ} \mathrm{C}$ is primarily related to PVDF carbon-hydrogen bond scission due to the bond strength of $\mathrm{C}-\mathrm{H}$ compared with the $\mathrm{C}-\mathrm{F}$ bond $\left(410\right.$ and $460 \mathrm{~kJ} \mathrm{~mol}^{-1}$, respectively) [40]. Also, the inclusion of the BT fillers within PVDF does not affect the degradation behaviour, contrary to the effect observed for the inclusion of CNT. The main reason for this fact is due to the formation of different polymer / nanoparticle interfaces as well as to the differences in the thermal conductivity of the fillers [27, 41].

Table 2 - Characteristic thermodegradation temperatures $\left(T_{5} \%, T_{p}\right)$ for SBS, SEBS, PVDF and their nanocomposites. Data has been extracted from Figure 3.

\begin{tabular}{|c|c|c|}
\hline Sample & $\boldsymbol{T}_{\mathbf{5} \%} \mathbf{\pm 2}\left({ }^{\circ} \mathbf{C}\right)$ & $\boldsymbol{T}_{\boldsymbol{p}} \mathbf{\pm 2}\left({ }^{\circ} \mathbf{C}\right)$ \\
\hline SBS & 374 & 453 \\
\hline SEBS & 391 & 439 \\
\hline $\mathbf{0 . 5 C N T / S E B S}$ & 392 & 443 \\
\hline 50BT/SEBS & 393 & 443 \\
\hline $\mathbf{0 . 5 C N T / 5 0 B T / S E B S ~}$ & 406 & 440 \\
\hline PVDF & 459 & 480 \\
\hline 0.5CNT/PVDF & 436 & 470 \\
\hline 50BT/PVDF & 459 & 482 \\
\hline
\end{tabular}

The addition of either CNTs or BT into the SEBS matrix slightly increases the thermal stability of the nanocomposite as indicated by the increase of $T_{5 \%}$ values up to $406{ }^{\circ} \mathrm{C}$. This arises from the high thermal stability of both CNTs and BT, which present a negligible weight loss within the studied region [42]. The maximum degradation rate is markedly decreased for the nanocomposites having $50 \mathrm{wt} . \% \mathrm{BT}$ as only the polymeric phase is being degraded. The char yield at $600{ }^{\circ} \mathrm{C}$, once the polymeric phase has been completely degraded, is about 48 and $50 \%$ for $0.5 \mathrm{CNT} / 50 \mathrm{BT} / \mathrm{SEBS}$ and 50BT/SEBS respectively. This residue corresponds to the inorganic phase within the composite and matches well with the initially prepared formulation. SBS and PVDF composites with 50 wt.\% of BT shows similar behaviour than SEBS matrix. Thermal stability increases 
slightly for larger filler contents and for $0.5 \mathrm{CNT} / 50 \mathrm{BT} / \mathrm{SEBS}$, the synergetic effect on thermal stability is not observed.

\subsection{Mechanical properties}

The mechanical performance of the soft (SBS and SEBS) and harder (PVDF) polymeric matrices reinforced with both nanofillers have been evaluated through uniaxial tensile testing. Representative tensile stress-strain curves are depicted in Figure 4, while the most relevant parameters extracted from tensile testing are summarized in Table 3.
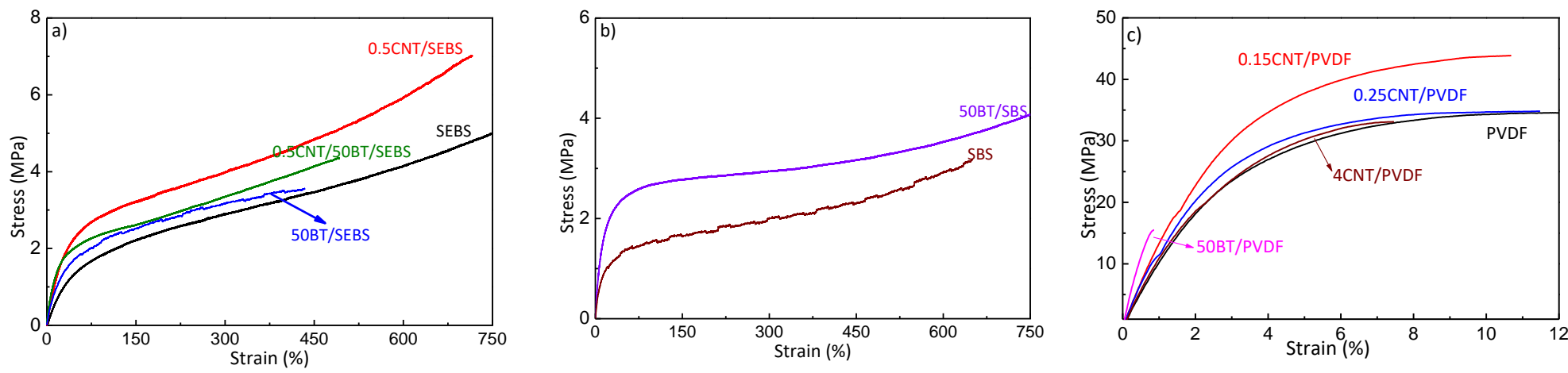

Figure 4 - Representative tensile stress-strain curves of SEBS (a) and SBS nanocomposites (b) and PVDF-based nanocomposites (c).

As shown in Figure 4a) and b), neat SBS and SEBS present a rubbery behaviour with an elongation at yield $\left(\varepsilon_{y}\right)$ of 27 and $44 \%$ respectively, and an elongation at break $\left(\varepsilon_{b}\right)$ of 651 and $778 \%$ respectively. This larger deformability arises from the butadiene part which provides SBS-family polymers the rubbery-like behaviour, while styrene yields the tough hard character $[39,43,44]$. Interestingly, CNT and/or BT incorporation does not notably reduce the high ductility of the nanocomposites as $\varepsilon_{b}$ values exceeding $450 \%$ are obtained. This large deformability contrasts with the often-encountered issues of poor flexibility obtained when such large filler loadings are used in polymer composites [29]. 
Table 3. Mechanical properties of the SBS, SEBS and PVDF composites with CNT and BT.

\begin{tabular}{|c|c|c|c|c|c|}
\hline \multirow[t]{2}{*}{ Material } & \multicolumn{2}{|c|}{ Yield Point } & \multirow{2}{*}{$\begin{array}{c}\text { Initial } \\
\text { Modulus } \\
\text { (MPa) }\end{array}$} & \multirow{2}{*}{$\begin{array}{c}\text { at } 100 \% \\
\text { Stress } \\
\text { (MPa) }\end{array}$} & \multirow{2}{*}{$\begin{array}{c}\text { at } 300 \% \\
\text { Stress } \\
\text { (MPa) }\end{array}$} \\
\hline & $\begin{array}{c}\text { Strain } \\
(\%)\end{array}$ & $\begin{array}{l}\text { Stress } \\
\text { (MPa) }\end{array}$ & & & \\
\hline SEBS & 44.3 & 1.9 & 4.6 & 1.9 & 2.9 \\
\hline 50BT/SEBS & 38.7 & 2.2 & 8.3 & 2.2 & 3.2 \\
\hline $0.5 \mathrm{CNT} / \mathrm{SEBS}$ & 36.4 & 2.6 & 9.8 & 2.9 & 4.0 \\
\hline 0.5CNT/50BT/SEBS & 18.5 & 2.0 & 14.5 & 2.4 & 3.4 \\
\hline SBS & 26.9 & 2.2 & 11.1 & 2.2 & 2.6 \\
\hline 50BT/SBS & 24.6 & 2.6 & 15.7 & 2.7 & 2.9 \\
\hline & & & & at $0.5 \%$ & at $5 \%$ \\
\hline PVDF & 3.4 & 42.0 & 1023 & 3.3 & 33.0 \\
\hline 0.15CNT/PVDF & 3.0 & 33.4 & 1246 & 5.4 & 29.4 \\
\hline 0.25CNT/PVDF & 3.1 & 32.3 & 1292 & 7.0 & 37.7 \\
\hline 4CNT/PVDF & 3.1 & 32.3 & 1199 & 6.8 & 31.3 \\
\hline 50BT/PVDF & 0.9 & 15.6 & 2096* & 10.8 & - \\
\hline
\end{tabular}

*just measure up to $0.5 \%$ due low maximum strain.

The incorporation of nanofillers effectively enhances the elastic modulus of the nanocomposites as the addition of only $0.5 \mathrm{wt} . \% \mathrm{CNTs}$ is able to increase the initial modulus $(E)$ of neat SEBS from 4.6 to $9.8 \mathrm{MPa}$ [45] as is shown in table 3. This result indicates the effective mechanical reinforcing effect of CNTs in elastomeric composites with lower nanofillers contents, compared with larger BT contents (50 wt.\%) required to reach such an increase in $E$. Moreover, for tri-composite, the concomitant addition of CNTs and BT results in an almost three-fold increase in E. Altogether, these results indicate that a good compatibility between both the reinforcing phase and the polymeric matrix has been obtained, even for filler concentrations as high as $50 \mathrm{wt} \%$. Taking into account the nanofiller contents, CNTs incorporation results a more effective approach to mechanically reinforce elastomeric SBS and SEBS in comparison with BT.

As depicted in Figure 4b, neat PVDF is characterized by a semi-ductile behaviour with a $\varepsilon_{y}$ of $3.4 \%$, a $\varepsilon_{b}$ of $12 \%$ and a Young's modulus of $923 \mathrm{MPa}$ [46]. CNT incorporation results in a progressive decrease of $\varepsilon_{b}$ up to $7.5 \%$ for 4CNT/PVDF nanocomposites, 
which is a commonly found trend in nanocomposites having carbon nanotubes as a fillers [47-49]. For the 0.25 CNT/PVDF nanocomposites, the mechanical behaviour is the same, within experimental error, when compared to neat PVDF due to the low filler volume fraction. The elongation at break of the 50BT/PVDF nanocomposite is markedly lowered to $0.9 \%$ as a result of the large content of ceramic nanoparticles. Such decrease is comparable to that previously reported for polyamide 11 and polyimide nanocomposites having a similar degree of reinforcement $[50,51]$. An increase of $E$ up to $1138 \mathrm{MPa}$ is achieved at low CNT loadings, while further CNT enhancement is accompanied by a lowering of $E$ to values comparable with the neat PVDF. This behaviour can be explained in terms of poor interfacial adhesion between the fillers and the hosting PVDF, resulting in inefficient local stress transference $[52,53]$. From the other side, the elastic modulus of PVDF shows a twofold increase up to $2091 \mathrm{Mpa}$ after the incorporation of $50 \mathrm{wt} . \% \mathrm{BT}$.

Composite materials based in PVDF do not show similar behaviour in mechanical reinforcement as the SBS-family polymers. The harder polymer, with $E \approx 1 \mathrm{GPa}$, presents a slightly increase in initial modulus for several CNTs contents, up to $4 \mathrm{wt}$. $\%$, near 1.2 GPa. For BT/PVDF composite, the $E$ duplicates compared to neat polymer, resulting in larger rigidity materials, when compared to PVDF. Compared the matrices, mechanical reinforcement with BT is similar for SEBS and PVDF (nearly duplicates the $E$ in both composites), but CNTs in PVDF almost shows no increase in initial modulus. BT/SBS composite presents higher initial modulus than the neat polymer, but the increase is lower when compared to the SEBS matrix, the structure of the triblock copolymer influencing, therefore, the mechanical reinforcement effect of the filler.

The nanocomposites present potential for mechanical sensing applications as they are able to withstand large deformations without rupture, for softer matrixes. Typically, thermoplastic and elastomeric materials present a hysteresis cycle upon loading- 
unloading whose area increases with the applied strain [6]. The occurrence of this hysteresis loop is known as Mullins effect and emerges due to the fact that under cyclic loading the strain cannot follow the approved stress [54]. It should be noted that different strain values were applied to ensure that applied deformations were within the linear elastic region. Overall, uniaxial stress-strain mechanical cycles in the polymers shows fast recovering to initial point after external applied stress for both neat PVDF (Figure 5a) and SBS-family polymers (Figure 5b). For neat PVDF at $1 \%$ of deformation, it is observed a slight mechanical fatigue, but suitable for pressure-sensing applications (Figure 5a).
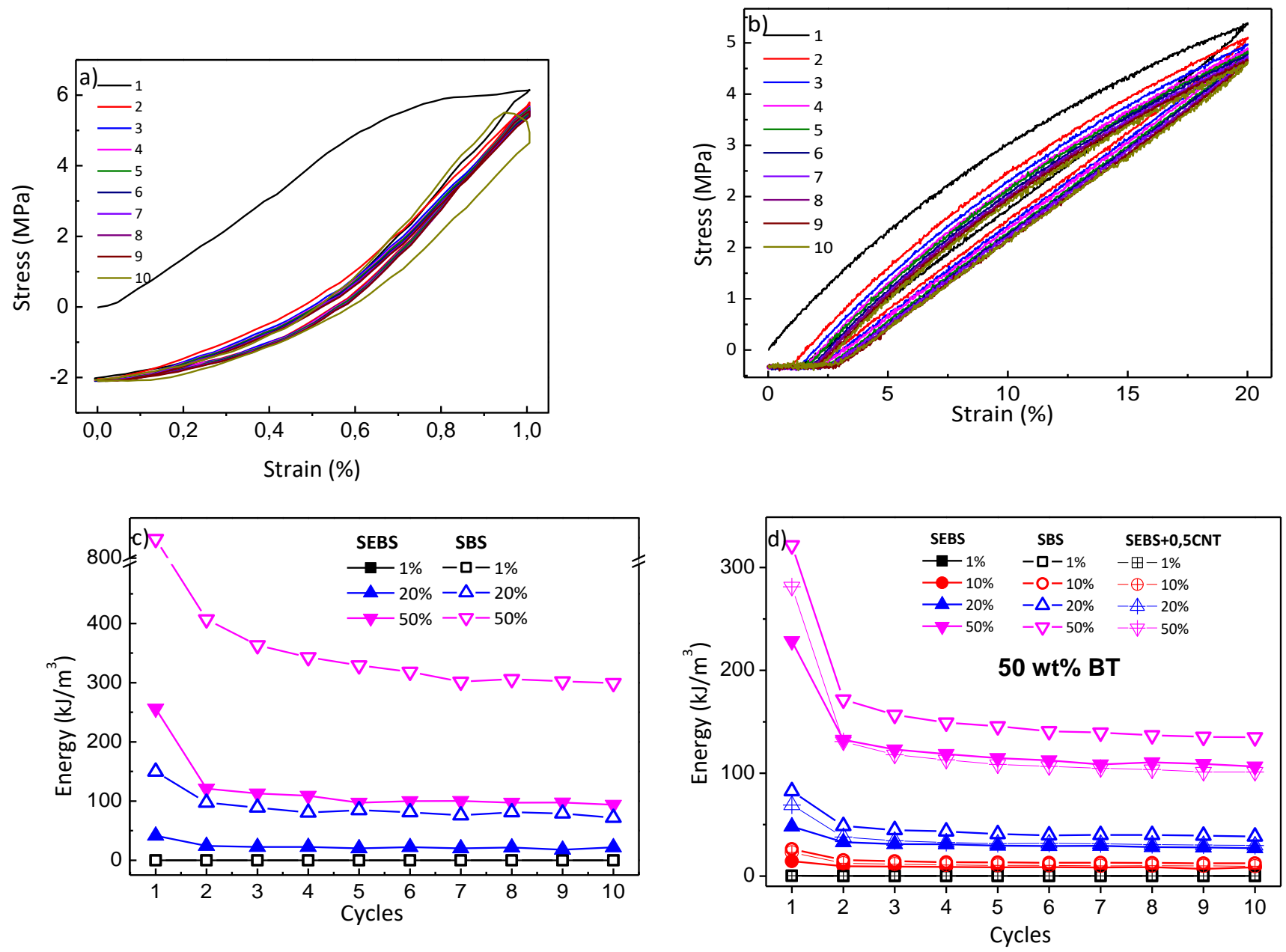

Figure 5 - Mechanical hysteresis curves of neat polymers and their corresponding composites: Response of a) neat PVDF under mechanical cycling deformation at $1 \%$ of strain and b) neat SBS under mechanical cycling deformation at $20 \%$ of strain. c) mechanical energy losses (hysteresis) results of neat SBS and SEBS for different cycles 
under different strains percentages and (d) mechanical hysteresis response of SBS and SEBS reinforced with $50 \mathrm{wt}$ \% BT.

Further, for neat SBS, it is observed that stresses under retraction become negative due to buckling of samples. The mechanical energy losses obtained from the hysteresis curves upon loading-unloading for neat SBS and SEBS and their nanocomposites containing 50 wt.\% BT when strains up to $50 \%$ are applied, it is shown in Figure 5c and 5d respectively that plastic deformations can be induced due to buckling of the samples. It is observed that elastomeric polymers and their nanocomposites show cyclic properties up to large strains. The mechanical hysteresis decreases during the initial three cycles and then trends to a similar value for all the applied cycles. For strains of 1 and $10 \%$ applied to the neat polymers, a hysteresis of few $\mathrm{kJ} \cdot \mathrm{m}^{-3}$ is observed (Figure $5 \mathrm{c}$ ). When the applied strain is increased up to 20 and $50 \%$, hysteresis values of $23.4 \mathrm{~kJ} \cdot \mathrm{m}^{-3}$ and $118.5 \mathrm{~kJ} \cdot \mathrm{m}^{-3}$ were obtained for SEBS, while SBS showed values of $89.0 \mathrm{~kJ} \cdot \mathrm{m}^{-3}$ and $381.7 \mathrm{~kJ} \cdot \mathrm{m}^{-3}$ respectively. The larger hysteresis value of SBS arises from its larger hard (styrene) content [6], while energy loss increases with applied strain as characteristic of rubber-like materials after the Mullins effect [54].

As depicted in Figure 5d, upon the incorporation of $50 \mathrm{wt}$ \% of BT, SBS matrix also shows a larger hysteresis response in comparison with SEBS. Additionally, the tricomposite SEBS sample (0.5CNT/50BT/SEBS) presents hysteresis values between the elastomeric polymers (higher than SEBS and smaller than SBS). For $1 \%$ of strain, all the composite samples present a hysteresis of some tens $\mathrm{J} \cdot \mathrm{m}^{-3}$, while $10 \%$ a hysteresis yields $9.2 \mathrm{~kJ} \cdot \mathrm{m}^{-3}, \quad 14.6 \mathrm{~kJ} \cdot \mathrm{m}^{-3}$ and $11.8 \mathrm{~kJ} \cdot \mathrm{m}^{-3}$ for 50BT/SEBS, 50BT/SBS and 0.5CNT/50BT/SEBS respectively. When the strain is increased up to $50 \%$, hysteresis values of $126.4 \mathrm{~kJ} \cdot \mathrm{m}^{-3}, 163.2 \mathrm{~kJ} \cdot \mathrm{m}^{-3}$ and $126.9 \mathrm{~kJ} \cdot \mathrm{m}^{-3}$ for $50 \mathrm{BT} / \mathrm{SEBS}, 50 \mathrm{BT} / \mathrm{SBS}$ and 0.5CNT/50BT/SEBS are obtained respectively. The hysteresis is larger in the harder 
matrix (SBS) and increases with increasing strain. For composites with 50 wt.\% BT the hysteresis decreases when compared with neat polymer.

\subsection{Electrical conductivity and dielectric properties}

Electrical conductivity and dielectric properties of the polymers reinforced with CNT and BT have been evaluated by performing I-V curves and dielectric spectroscopy in the $200 \mathrm{~Hz}$ to $1 \mathrm{MHz}$ region. Figure 6a shows obtained I-V curves for PVDF reinforced with carbon nanotubes.
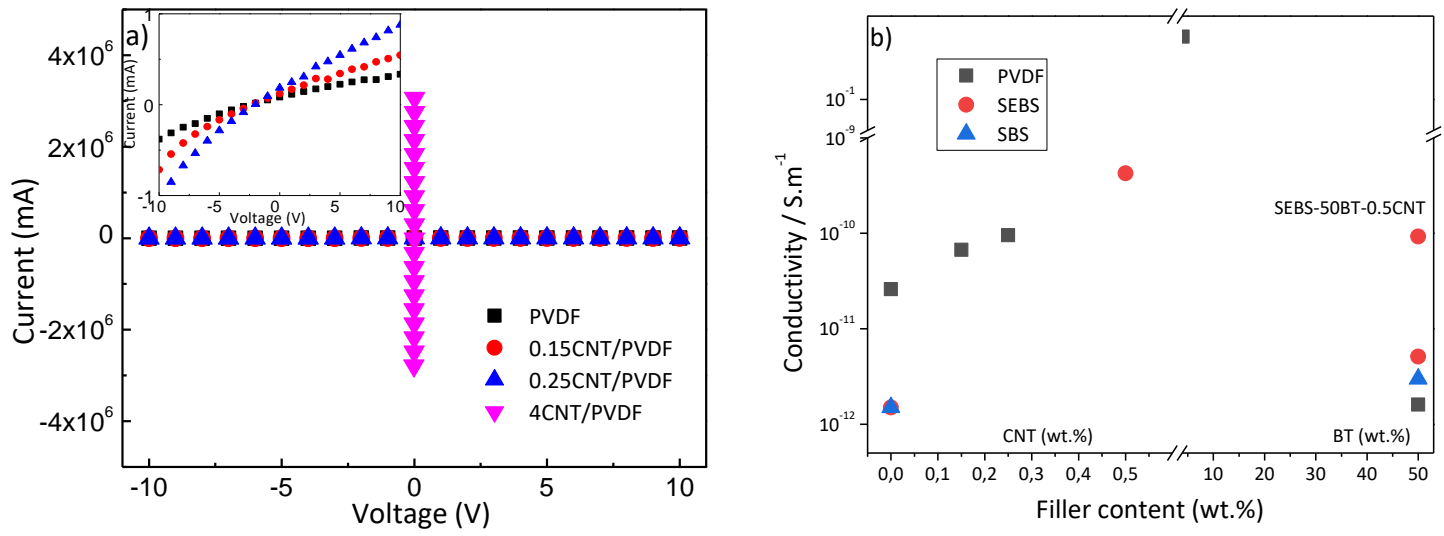

Figure 6 - a) Current-voltage ( $I-V)$ curves for PVDF and nanocomposites up to 4 wt.\% CNTs and b) bulk electrical conductivities of PVDF and SEBS and nanocomposites as a function of CNTs loading.

Lower CNTs contents into PVDF do not strongly increase the electrical conductivity of the composites. The percolation threshold is above 0.25 wt.\% CNTs. Composites with 4 wt.\% show an electrical conductivity several orders of magnitude larger than the composite with 0.25 wt.\% CNTs (Figure 6a). The dc electric conductivity $(\sigma)$ for PVDF, SBS and SEBS nanocomposites as a function of BT and CNTs concentration is shown in Figure $6 \mathrm{~b}$. The electrical conductivity of neat PVDF and SEBS are $2.6 \times 10^{-10} \mathrm{~S} \cdot \mathrm{m}^{-1}$ and $1.44 \times 10^{-12} \mathrm{~S} \cdot \mathrm{m}^{-1}$ respectively, which matches well with previously reported values for such polymers $[55,56]$. A strong increase of the electrical conductivity up to $0.41 \mathrm{~S} \cdot \mathrm{m}^{-1}$ 
is observed after the addition of $4 \mathrm{wt} . \%$ of CNTs. This increase of $\sigma$ by ten orders of magnitude with respect to neat PVDF is due to the formation of an electrically conducting network within the nanocomposite. The formation of such an interconnected structure that allows electron transport along the CNTs network is described by the percolation theory [57]. Typically, CNT/polymer nanocomposites display percolation thresholds $\left(\rho_{c}\right.$, filler concentration at which the transition from the insulating state to the conducting state occurs) in the range of $0.1-2 \mathrm{wt} \%$, strongly depending on the aspect ratio, intrinsic conductivity and dispersion of the nanofillers within the matrix $[58,59]$. Based on the results shown in Figure 6b, it can be concluded that the $\sigma_{c}$ of CNT/PVDF and CNT/SEBS nanocomposites is achieved at concentrations larger than 0.25 and $0.5 \mathrm{wt} . \%$, respectively. It should be taken into account that the addition of BT does not modify the electrical conductivity of the prepared materials as SBS, SEBS and PVDF having BT concentrations of $50 \mathrm{wt} . \%$ display a $\sigma$ within the same magnitude than their corresponding neat counterparts, as BT is also a dielectric material (Figure 6b).

The dielectric response of the nanocomposites measured from $500 \mathrm{~Hz}$ to $1 \mathrm{MHz}$ is shown in Figure 7, in which the dielectric constant and $\tan \delta$ as a function of the frequency are shown in Figure 7a) and 7b), respectively.
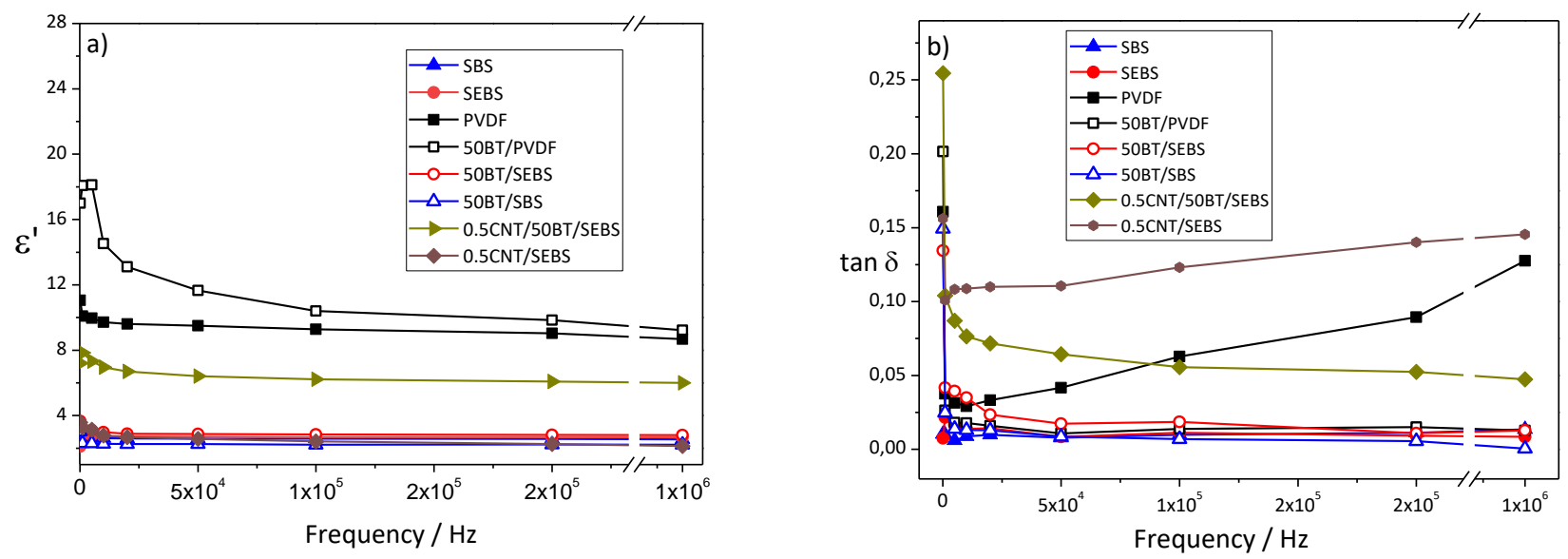

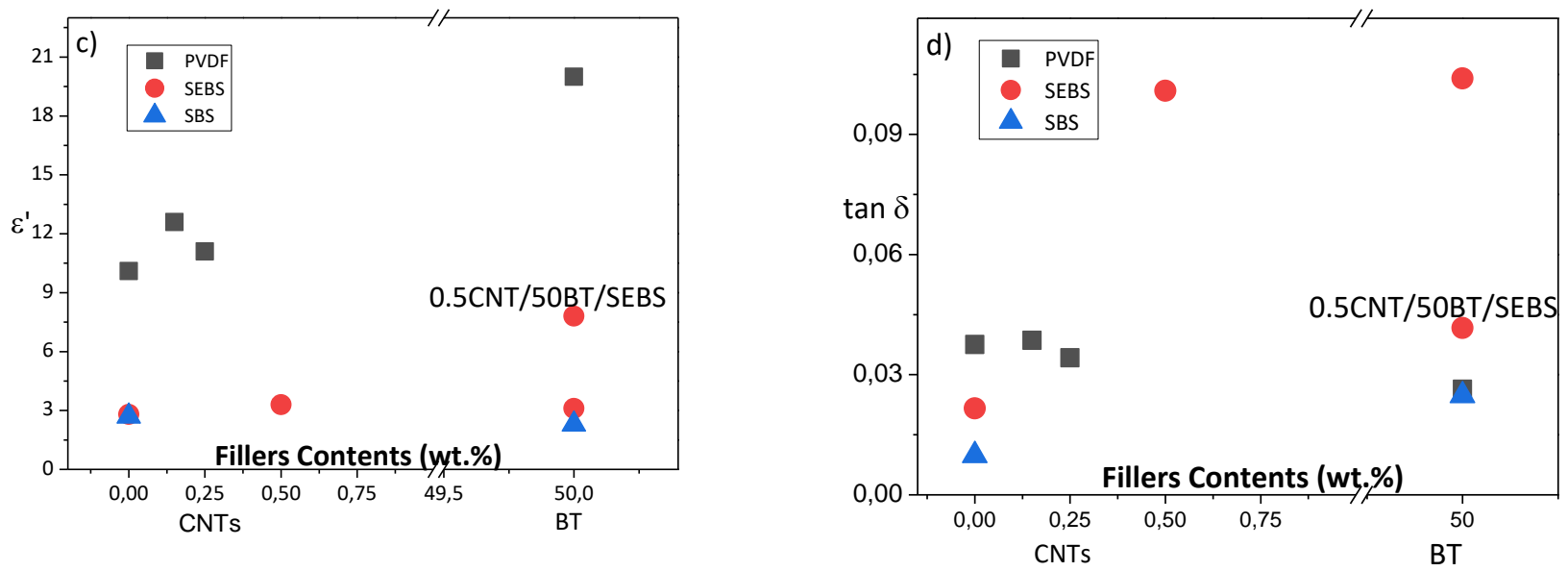

Figure $7-$ a) Real part of the permittivity and b) $\tan \delta$ as a function of frequency for neat polymers and their nanocomposites, respectively and real part of the permittivity (c) and $\tan \delta(\mathrm{d})$ at $1 \mathrm{kHz}$ for several composites with different matrices and fillers.

The frequency dielectric response shows the typical behaviour of the polymer materials[60] and this behaviour is practically same for all nanocomposites i.e, the dielectric constant $\left(\varepsilon^{\prime}\right)$ and tan delta decreases with increasing the frequency.

To demonstrate the effect of the filler on the polymer matrix, the values of the dielectric constant $\left(\varepsilon^{\prime}\right)$ and $\tan \delta$ obtained for a frequency of $1 \mathrm{kHz}$ are shown in Figure $7 \mathrm{c}$ and $7 \mathrm{~d})$, respectively.

At $1 \mathrm{kHz}$, neat PVDF shows a dielectric constant of nearly 10, which slightly increases in CNTs composites, up to 13 and 11 with 0.15 and 0.25 wt.\% CNTs nanocomposite (Figure 7c). This decrease in $\varepsilon^{\prime}$ for larger CNTs contents results from the hindering of the dipolar dynamic by the numerous CNT/PVDF interfaces [61]. Ceramic nanofillers lead to larger values of the dielectric constant $\varepsilon^{\prime} \approx 20$ for 50BT/PVDF due to the larger dielectric constant of the filler and from the influence of interfacial polarization effects known as Maxwell-Wagner-Sillars (MWS) contributions [62, 63]. This fact is also demonstrated through the $\tan \delta$ due to interfacial charge accumulation (Figure $7 d$ ). With respect to SBS and SEBS, no relevant differences in the composites are observed for the addition of BT or CNT due to the fact when the CNT content is below the percolation 
threshold, the CNT does not form a conductive network and the nanocomposite is highly resistive, similar to BT nanocomposites. The dielectric constant increases with higher concentrations of both fillers as a result of the influence of particle distribution, polarization and interfacial polarization between the fillers and polymer matrix [30]. Interestingly, when both fillers are mixed together (0.5CNT/50BT/SEBS), the dielectric constant markedly increases from 2.8 to 7.8 , suggesting a synergetic effect of both reinforcements, combining both conductivity and interfacial polarization contributions.

\subsection{Piezocapacitive measurements}

The larger stretchability of the SBS-family with improved capacitance response shows a great potential for the development of force sensor arrays capable of providing a capacitance response variation when subject to an external stimulus (movements of the fingers, touch, human weight or others) [64]. Accordingly, we have evaluated the obtained changes in the capacitance $(\Delta C)$ as a function of applied static load $(50,100$, 200 and $400 \mathrm{~N}$ of force) in neat polymers and corresponding nanocomposites and the obtained results are shown in Figure 8. The measurements were performed without and after applied force.

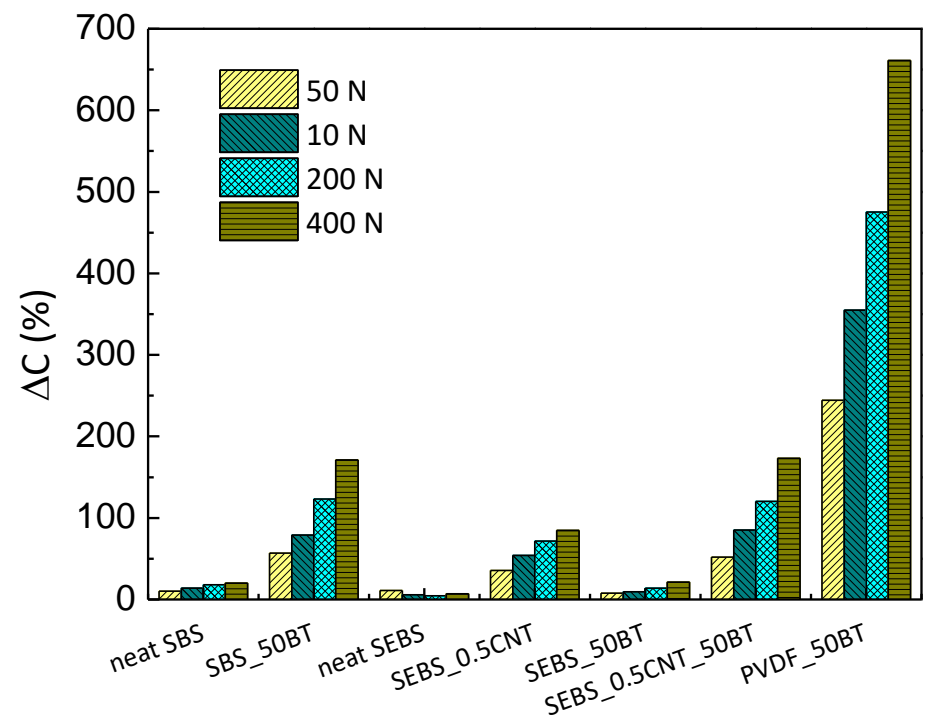


Figure 8 - Variation of the capacitance at $1 \mathrm{kHz}$ for different applied force of the polymers and composites with CNT and BT as nanofillers.

Neat polymers display a maximum increase on the capacitance of 7 and $20 \%$ upon the application of $400 \mathrm{~N}$ for SEBS and SBS respectively. It is worthy to note that a small amount of CNTs is able to result in a $\triangle C$ of $85 \%$ for the SEBS nanocomposite after the application of $400 \mathrm{~N}$. Such increase is due to the higher transverse polarizability when in the presence of carbon nanotubes $[65,66]$. BT also allows to increase markedly the obtained $\Delta C$, although its effect results more marked for the SBS nanocomposite. The concomitant addition of both CNTs and BT yields to a maximum $\triangle C$ of $173 \%$ upon the application of $400 \mathrm{~N}$. Such marked increase may be due to the combination of both electrically conducting CNTs and insulating BT which form microcapacitor structures at their interfaces [67]. Finally, a dramatic effect of BT on the $\Delta C$ is observed for the nanocomposite based on PVDF, reaching a maximum value of $661 \%$ when a force of $400 \mathrm{~N}$ was applied. These results highlight the potential of nanocomposites containing BT to be applied as sensing materials. Moreover, the performance of the BT-based nanocomposites could be prospectively improved upon the incorporation of a small amount of CNTs.

\section{Conclusions}

Barium titanate (BT) and carbon nanotubes (CNTs) have been incorporated into elastomeric and semi-ductile polymers to develop materials with potential load sensing applications. Electron microscopy observations reveal that a good dispersion of the nanoparticles within the polymeric matrix has been obtained even at a concentration of 50 wt.\%. FTIR results indicate that the prepared nanocomposites present physical interactions between constituents rather than chemical ones. Obtained nanocomposites 
remain thermally stable up to temperatures above $350{ }^{\circ} \mathrm{C}$. Interestingly, BT and CNTs incorporation into the elastomeric matrices increases the initial modulus of the nanocomposites up to 3-times while keeping the ductility barely unchanged with $\varepsilon_{b}$ exceeding $450 \%$. On the contrary, nanoparticle addition limits the ductility of PVDF, especially when 50 wt.\% BT is added.

Following the Mullins effect, mechanical energy losses up to $381.7 \mathrm{~kJ} \cdot \mathrm{m}^{-3}$ were obtained for neat SBS when a strain of $50 \%$ was applied. Such energy losses, extracted from the hysteresis curves upon successive uniaxial loading-unloading cycles, decreased up to $163.2 \mathrm{~kJ} \cdot \mathrm{m}^{-3}$ upon the incorporation of $50 \mathrm{wt} . \%$ BT. dc conductivity measurements reveal a marked conductivity increase upon $\mathrm{CNT}$ addition, with a percolation threshold of 1.24 and 0.98 wt.\% for CNT/PVDF and CNT/SEBS nanocomposites respectively. On the contrary, the presence of BT does not affect the conductivity of the nanocomposites as $\sigma$ remains within the same magnitude than their corresponding neat counterparts. The dielectric constant for SEBS with CNT and BT is markedly larger, suggesting a synergetic effect of both reinforcements. Finally, the changes in the capacitance $(\Delta C)$ as a function of applied static load in neat and nanocomposite materials were evaluated. Thanks to the combination of both electrically conducting CNTs and insulating BT which are able to form microcapacitor structures at their interfaces, their concomitant addition into polymers yields a maximum $\Delta C$ of $173 \%$. The materials here developed display suitable properties to be applied in force sensor devices as they are capable of providing electric response upon the application of loads.

\section{Acknowledgements}

The authors thank the FCT (Fundação para a Ciência e Tecnologia) for financial support under the framework of Strategic Funding grants UID/FIS/04650/2019, UID/EEA/04436/2013 and UID/QUI/0686/2016; and projects no. PTDC/EEI- 
SII/5582/2014 and PTDC/FIS-MAC/28157/2017. The authors also thank the FCT for financial support under grants SFRH/BD/140242/2018 (T.M.), SFRH/BPD/110914/2015 (P.C.). SFRH/BPD/112547/2015 (C.M.C.) as well POCH and European Union. Financial support from the Spanish Ministry of Economy and Competitiveness (MINECO) through project MAT2016-76039-C4-3-R (AEI/FEDER, UE) (including FEDER financial support) and from the Basque Government Industry and Education Departments under the ELKARTEK, HAZITEK and PIBA (PIBA-2018-06) programs, respectively, is also acknowledged. The authors also thank to Dynasol Elastómeros for supplying the TPE polymer.

\section{References}

[1] Kim J-Y, Lee J, Lee WH, Kholmanov IN, Suk JW, Kim T, et al. Flexible and Transparent Dielectric Film with a High Dielectric Constant Using Chemical Vapor Deposition-Grown Graphene Interlayer. ACS Nano. 2014;8(1):269-74.

[2] Wang Y, Xing C, Guan J, Li Y. Towards Flexible Dielectric Materials with High Dielectric Constant and Low Loss: PVDF Nanocomposites with both Homogenously Dispersed CNTs and Ionic Liquids Nanodomains. Polymers. 2017;9(11).

[3] Shi L, Yang R, Lu S, Jia K, Xiao C, Lu T, et al. Dielectric gels with ultra-high dielectric constant, low elastic modulus, and excellent transparency. NPG Asia Materials. 2018;10(8):821-6.

[4] Kashi S, Gupta RK, Baum T, Kao N, Bhattacharya SN. Dielectric properties and electromagnetic interference shielding effectiveness of graphene-based biodegradable nanocomposites. Materials \& Design. 2016;109:68-78.

[5] Huang X, Sun B, Zhu Y, Li S, Jiang P. High-k polymer nanocomposites with 1D filler for dielectric and energy storage applications. Progress in Materials Science. $2019 ; 100: 187-225$.

[6] Costa P, Ribeiro S, Lanceros-Mendez S. Mechanical vs. electrical hysteresis of carbon nanotube/styrene-butadiene-styrene composites and their influence in the electromechanical response. Composites Science and Technology. 2015;109:1-5.

[7] Drozdov AD. A model for the mechanical response of composites with thermoplasticelastomer matrices. Composites Science and Technology. 2006;66(15):2648-63. 
[8] Ji M, Deng H, Yan D, Li X, Duan L, Fu Q. Selective localization of multi-walled carbon nanotubes in thermoplastic elastomer blends: An effective method for tunable resistivity-strain sensing behavior. Composites Science and Technology. 2014;92:16-26. [9] Zhang X, Shen Y, Xu B, Zhang Q, Gu L, Jiang J, et al. Giant Energy Density and Improved Discharge Efficiency of Solution-Processed Polymer Nanocomposites for Dielectric Energy Storage. Advanced Materials. 2016;28(10):2055-61.

[10] Carpi F, Gallone G, Galantini F, De Rossi D. Silicone-Poly(hexylthiophene) Blends as Elastomers with Enhanced Electromechanical Transduction Properties. Advanced Functional Materials. 2008;18(2):235-41.

[11] Regtien PPL. 5 - Capacitive Sensors. In: Regtien PPL, editor. Sensors for Mechatronics. Oxford: Elsevier; 2012. p. 101-24.

[12] Martins P, Lopes AC, Lanceros-Mendez S. Electroactive phases of poly(vinylidene fluoride): Determination, processing and applications. Progress in Polymer Science. 2014;39(4):683-706.

[13] Tanaka T, Montanari GC, Mulhaupt R. Polymer nanocomposites as dielectrics and electrical insulation-perspectives for processing technologies, material characterization and future applications. IEEE Transactions on Dielectrics and Electrical Insulation. 2004;11(5):763-84.

[14] Ribeiro C, Costa CM, Correia DM, Nunes-Pereira J, Oliveira J, Martins P, et al. Electroactive poly(vinylidene fluoride)-based structures for advanced applications. Nature Protocols. 2018;13:681.

[15] Jin Y, Xia N, Gerhardt RA. Enhanced dielectric properties of polymer matrix composites with BaTiO3 and MWCNT hybrid fillers using simple phase separation. Nano Energy. 2016;30:407-16.

[16] Costa P, Silva J, Sencadas V, Simoes R, Viana JC, Lanceros-Méndez S. Mechanical, electrical and electro-mechanical properties of thermoplastic elastomer styrenebutadiene-styrene/multiwall carbon nanotubes composites. Journal of Materials Science. 2013;48(3):1172-9.

[17] Kobayashi Y, Kurosawa A, Nagao D, Konno M. Fabrication of barium titanate nanoparticles-polymethylmethacrylate composite films and their dielectric properties. Polymer Engineering \& Science. 2009;49(6):1069-75.

[18] Xie L, Huang X, Wu C, Jiang P. Core-shell structured poly(methyl methacrylate)/BaTiO3 nanocomposites prepared by in situ atom transfer radical 
polymerization: a route to high dielectric constant materials with the inherent low loss of the base polymer. Journal of Materials Chemistry. 2011;21(16):5897-906.

[19] Lizundia E, Sarasua JR, D'Angelo F, Orlacchio A, Martino S, Kenny JM, et al. Biocompatible Poly(L-lactide)/MWCNT Nanocomposites: Morphological Characterization, Electrical Properties, and Stem Cell Interaction. Macromolecular Bioscience. 2012;12(7):870-81.

[20] Lizundia E, Oleaga A, Salazar A, Sarasua JR. Nano- and microstructural effects on thermal properties of poly (l-lactide)/multi-wall carbon nanotube composites. Polymer. 2012;53:2412-21.

[21] Sahoo NG, Rana S, Cho JW, Li L, Chan SH. Polymer nanocomposites based on functionalized carbon nanotubes. Progress in Polymer Science. 2010;35(7):837-67.

[22] Liu L, Grunlan JC. Clay Assisted Dispersion of Carbon Nanotubes in Conductive Epoxy Nanocomposites. Advanced Functional Materials. 2007;17(14):2343-8.

[23] Jaschin PW, Bhimireddi R, Varma KBR. Enhanced Dielectric Properties of LaNiO3/BaTiO3/PVDF: A Three-Phase Percolative Polymer Nanocrystal Composite. ACS Applied Materials \& Interfaces. 2018;10(32):27278-86.

[24] He D, Wang Y, Chen X, Deng Y. Core-shell structured BaTiO3@Al2O3 nanoparticles in polymer composites for dielectric loss suppression and breakdown strength enhancement. Composites Part A: Applied Science and Manufacturing. 2017;93:137-43.

[25] Wan Y-J, Zhu P-L, Yu S-H, Yang W-H, Sun R, Wong C-P, et al. Barium titanate coated and thermally reduced graphene oxide towards high dielectric constant and low loss of polymeric composites. Composites Science and Technology. 2017;141:48-55.

[26] Wang H, Fu Q, Luo J, Zhao D, Luo L, Li W. Three-phase Fe3O4/MWNT/PVDF nanocomposites with high dielectric constant for embedded capacitor. Applied Physics Letters. 2017;110(24):242902.

[27] Mendes SF, Costa CM, Caparros C, Sencadas V, Lanceros-Méndez S. Effect of filler size and concentration on the structure and properties of poly(vinylidene fluoride)/BaTiO3 nanocomposites. Journal of Materials Science. 2012;47(3):1378-88.

[28] Araújo MC, Costa CM, Lanceros-Méndez S. Evaluation of dielectric models for ceramic/polymer composites: Effect of filler size and concentration. Journal of NonCrystalline Solids. 2014;387:6-15.

[29] Costa CM, Firmino Mendes S, Sencadas V, Ferreira A, Gregorio R, Gómez Ribelles $\mathrm{JL}$, et al. Influence of processing parameters on the polymer phase, microstructure and 
macroscopic properties of poly(vinilidene fluoride)/ $\mathrm{Pb}(\mathrm{Zr} 0.53 \mathrm{Ti} 0.47) \mathrm{O} 3$ composites. Journal of Non-Crystalline Solids. 2010;356(41):2127-33.

[30] Poudel A, Coffey A, Kennedy J, Lyons S, Thomas K, Walsh P. Dielectric Polarization Enhancement of Thermoplastic Elastomers for Sensing and Energy Harvesting Applications2015.

[31] Yamada S, Hirao K, Yamauchi Y, Kanzaki S. High strength B4C-TiB2 composites fabricated by reaction hot-pressing. Journal of the European Ceramic Society. 2003;23(7):1123-30.

[32] Saikrasun S, Bualek-Limcharoen S, Kohjiya S, Urayama K. Thermotropic liquidcrystalline copolyester (Rodrun LC3000)/thermoplastic elastomer (SEBS) in situ composites: II. Mechanical properties and morphology of monofilaments in comparison with extruded strands. Journal of Applied Polymer Science. 2003;90(2):518-24.

[33] Müller F, Ferreira CA, Franco L, Puiggalí J, Alemán C, Armelin E. New Sulfonated Polystyrene and Styrene-Ethylene/Butylene-Styrene Block Copolymers for Applications in Electrodialysis. The Journal of Physical Chemistry B. 2012;116(38):11767-79.

[34] Saikrasun S, Amornsakchai T. Thermo-oxidative decomposition kinetics of elastomeric composites based on styrene-(ethylene-butylene)-styrene triblock copolymer and organomontmorillonite. Journal of Applied Polymer Science. 2011;120(6):3337-49. [35] Ganguly A, Bhowmick AK. Sulfonated Styrene-(ethylene-co-butylene)styrene/Montmorillonite Clay Nanocomposites: Synthesis, Morphology, and Properties. Nanoscale Research Letters. 2007;3(1):36.

[36] Elumalai V, Annapooranan R, Ganapathikrishnan M, Sangeetha D. A synthesis study of phosphonated PSEBS for high temperature proton exchange membrane fuel cells. Journal of Applied Polymer Science. 2018;135(10):45954.

[37] Kamalasanan MN, Kumar ND, Chandra S. Structural and microstructural evolution of barium titanate thin films deposited by the sol-gel process. Journal of Applied Physics. 1994;76(8):4603-9.

[38] Parambath Kanoth B, Claudino M, Johansson M, Berglund LA, Zhou Q. Biocomposites from Natural Rubber: Synergistic Effects of Functionalized Cellulose Nanocrystals as Both Reinforcing and Cross-Linking Agents via Free-Radical Thiol-ene Chemistry. ACS Applied Materials \& Interfaces. 2015;7(30):16303-10.

[39] Chi WS, Hwang S, Lee S-J, Park S, Bae Y-S, Ryu DY, et al. Mixed matrix membranes consisting of SEBS block copolymers and size-controlled ZIF-8 nanoparticles for CO2 capture. Journal of Membrane Science. 2015;495:479-88. 
[40] Botelho G, Lanceros-Mendez S, Gonçalves AM, Sencadas V, Rocha JG. Relationship between processing conditions, defects and thermal degradation of poly(vinylidene fluoride) in the $\beta$-phase. Journal of Non-Crystalline Solids. 2008;354(1):72-8.

[41] Huang C, Qian X, Yang R. Thermal conductivity of polymers and polymer nanocomposites. Materials Science and Engineering: R: Reports. 2018;132:1-22.

[42] George CN, Thomas JK, Kumar HP, Suresh MK, Kumar VR, Wariar PRS, et al. Characterization, sintering and dielectric properties of nanocrystalline barium titanate synthesized through a modified combustion process. Materials Characterization. 2009;60(4):322-6.

[43] Tucker PS, Barlow JW, Paul DR. Thermal, mechanical, and morphological analyses of poly(2,6-dimethyl-1,4-phenylene oxide)/styrene-butadiene-styrene copolymer blends. Macromolecules. 1988;21(6):1678-85.

[44] Kennedy JE, Lyons JG, Geever LM, Higginbotham CL. Synthesis and characterisation of styrene butadiene styrene-g-acrylic acid for potential use in biomedical applications. Materials Science and Engineering: C. 2009;29(5):1655-61.

[45] De Falco A, Goyanes S, Rubiolo GH, Mondragon I, Marzocca A. Carbon nanotubes as reinforcement of styrene-butadiene rubber. Applied Surface Science. 2007;254(1):262-5.

[46] Costa CM, Sencadas V, Pelicano I, Martins F, Rocha JG, Lanceros-Mendez S. Microscopic origin of the high-strain mechanical response of poled and non-poled poly(vinylidene fluoride) in the $\beta$-phase. Journal of Non-Crystalline Solids. 2008;354(32):3871-6.

[47] Spitalsky Z, Tasis D, Papagelis K, Galiotis C. Carbon nanotube-polymer composites: Chemistry, processing, mechanical and electrical properties. Progress in Polymer Science. 2010;35(3):357-401.

[48] Obarzanek-Fojt M, Elbs-Glatz Y, Lizundia E, Diener L, Sarasua J-R, Bruinink A. From implantation to degradation - are poly (L-lactide)/multiwall carbon nanotube composite materials really cytocompatible? Nanomedicine: Nanotechnology, Biology, and Medicine. 2014;10:1041-51.

[49] Nguyen-Tran H-D, Hoang V-T, Do V-T, Chun D-M, Yum Y-J. Effect of Multiwalled Carbon Nanotubes on the Mechanical Properties of Carbon Fiber-Reinforced Polyamide-6/Polypropylene Composites for Lightweight Automotive Parts. Materials. 2018;11(3). 
[50] Capsal J-F, Pousserot C, Dantras E, Dandurand J, Lacabanne C. Dynamic mechanical behaviour of polyamide 11/Barium titanate ferroelectric composites. Polymer. 2010;51(22):5207-11.

[51] Xu W, Ding Y, Jiang S, Ye W, Liao X, Hou H. High permittivity nanocomposites fabricated from electrospun polyimide/BaTiO3 hybrid nanofibers. Polymer Composites. 2016;37(3):794-801.

[52] Lizundia, E, Fortunati, E, Dominici, F, et al. PLLA-grafted cellulose nanocrystals: role of the CNC content and grafting on the PLA bionanocomposite film properties. Carbohydrate Polymers. 2016.

[53] Raquez JM, Habibi Y, Murariu M, Dubois P. Polylactide (PLA)-based nanocomposites. Progress in Polymer Science. 2013;38(10-11):1504-42.

[54] Diani J, Fayolle B, Gilormini P. A review on the Mullins effect. European Polymer Journal. 2009;45(3):601-12.

[55] Zhao Z, Zheng W, Yu W, Long B. Electrical conductivity of poly(vinylidene fluoride)/carbon nanotube composites with a spherical substructure. Carbon. 2009;47(8):2118-20.

[56] Li Y, Shimizu H. Toward a Stretchable, Elastic, and Electrically Conductive Nanocomposite: Morphology and Properties of Poly[styrene-b-(ethylene-co-butylene)-bstyrene]/Multiwalled Carbon Nanotube Composites Fabricated by High-Shear Processing. Macromolecules. 2009;42(7):2587-93.

[57] Grimmett G. Percolation and disordered systems. In: Bernard P, editor. Lectures on Probability Theory and Statistics: Ecole d'Eté de Probabilités de Saint-Flour XXVI-1996. Berlin, Heidelberg: Springer Berlin Heidelberg; 1997. p. 153-300.

[58] Bauhofer W, Kovacs JZ. A review and analysis of electrical percolation in carbon nanotube polymer composites. Composites Science and Technology. 2009;69(10):148698.

[59] Grossiord N, Kivit PJJ, Loos J, Meuldijk J, Kyrylyuk VA, van der Schoot P, et al. On the influence of the processing conditions on the performance of electrically conductive carbon nanotube/polymer nanocomposites. Polymer. 2008;49(12):2866-72.

[60] Reddy NV, Kumar CR, Rao VVRN. Dielectric properties of amorphous cellulose acetate-butyrate polymer films. Polymer International. 1993;32(4):381-4.

[61] Kochetov R, Andritsch T, Morshuis PHF, Smit JJ. Anomalous behaviour of the dielectric spectroscopy response of nanocomposites. IEEE Transactions on Dielectrics and Electrical Insulation. 2012;19(1):107-17. 
[62] Lizundia E, Maceiras A, Vilas JL, Martins P, Lanceros-Mendez S. Magnetic cellulose nanocrystal nanocomposites for the development of green functional materials. Carbohydrate Polymers. 2017;175:425-32.

[63] Roy S, Thakur P, Hoque NA, Bagchi B, Sepay N, Khatun F, et al. Electroactive and High Dielectric Folic Acid/PVDF Composite Film Rooted Simplistic Organic Photovoltaic Self-Charging Energy Storage Cell with Superior Energy Density and Storage Capability. ACS Applied Materials \& Interfaces. 2017;9(28):24198-209.

[64] Jang H, Yoon H, Ko Y, Choi J, Lee S-S, Jeon I, et al. Enhanced performance in capacitive force sensors using carbon nanotube/polydimethylsiloxane nanocomposites with high dielectric properties. Nanoscale. 2016;8(10):5667-75.

[65] Hazama Y, Ainoya N, Nakamura J, Natori A. Conductivity and dielectric constant of nanotube/polymer composites. Physical Review B. 2010;82(4):45204.

[66] Wang L, Dang Z-M. Carbon nanotube composites with high dielectric constant at low percolation threshold. Applied Physics Letters. 2005;87(4):42903.

[67] Madni I, Yu S, Sun R. Carbon nanotubes based composites with high dielectric constant and low loss. 2012 14th International Conference on Electronic Materials and Packaging (EMAP)2012. p. 1-6. 